\title{
ALGUNAS REFLEXIONES CRITICAS A PARTIR DE LA JURISPRUDENCIA SOBRE INMIGRACIÓN IRREGULAR
}


1. EL ESTADO SOCIAL ANTE EL FENÓMENO DE LA INMIGRACIÓN IRREGULAR. 2. LA LIBERTAD DE MIGRAR COMO DERECHO HUMANO Y COMO DERECHO CONSTITUCIONAL. 3. DERECHO A EMIGRAR, DERECHO A INMIGRAR Y SOBERANÍA NACIONAL. 4. RESTRICCIONES ADMISIBLES AL DERECHO A INMIGRAR. 5. LA CONDICIÓN DE «INMIGRANTE IRREGULAR»: RESPONSABILIDAD. 6. DERECHOS DE LOS INMIGRANTES IRREGULARES. 6.1. Naturaleza. 6.2. Contenido. 


\title{
ALGUNAS REFLEXIONES CRITICAS A PARTIR DE LA JURISPRUDENCIA SOBRE INMIGRACIÓN IRREGULAR
}

POR

\author{
ROBERTO URIARTE TORREALDAY
}

Universidad del País Vasco

\section{EL ESTADO SOCIAL ANTE EL FENÓMENO DE LA INMIGRACIÓN IRREGULAR}

El fenómeno de la inmigración irregular, al menos en sus actuales condiciones de masividad, constituye una realidad relativamente nueva en España; una realidad que no era previsible aún en el momento en que se redactó la Constitución de 1978. El desarrollo normativo y reglamentario en materia de extranjería, al igual que la correspondiente jurisprudencia, ha sufrido en este entretiempo numerosos avatares; avatares que no son sólo consecuencia de la improvisación, sino también de la dificultad intrínseca que plantea buscar una respuesta jurídica adecuada a un fenómeno con implicaciones tan complejas; y son consecuencia, en última instancia, de las profundas divergencias ideológicas que dividen a la sociedad a la hora de abordarlo.

Pero el Derecho, en cuanto instrumento de control social, necesita dar una respuesta a lo problemas sociales, por complejos que resulten. Y aunque la concreción de la política de extranjería a adoptar corresponda al debate político y al juego de las mayorías parlamentarias, en todo caso, sus líneas maestras deben estar inspiradas en las previsiones constitucionales y en última instancia, en los principios y valores que inspiran nuestro sistema constitucional. El presente trabajo pretende abordar la problemática de la inmigración irregular y más en 
concreto, las implicaciones constitucionales de aquella. Pero considero que antes de centrarse en el análisis de los preceptos constitucionales directamente atinentes a esta cuestión, conviene realizar una aproximación contextual, ubicando el problema dentro de nuestro modelo constitucional, ya que dicho modelo y los valores que lo inspiran deben ofrecernos no sólo las pautas hermenéuticas concretas, sino incluso el espíritu con el que aproximarnos al análisis de dicha problemática.

La Constitución española define ya desde su preámbulo, pero más nítidamente en su artículo uno, el modelo de Estado y los valores que lo sustentan. Se trata de un Estado social y democrático de derecho y sus valores superiores son la libertad, la igualdad, la justicia y el pluralismo. En consecuencia, es esta naturaleza social y democrática y son esos valores de libertad, justicia e igualdad los que deben inspirar el análisis de las normas constitucionales e infraconstitucionales en materia de extranjería y en particular, en relación a los derechos de los inmigrantes irregulares.

¿Posee alguna relevancia al respecto la definición social del Estado? Aunque es evidente que no todos los autores otorgan un mismo alcance a dicha tipificación, como consecuencia del profundo calado ideológico que la subyace, resulta evidente también que esta no carece de consecuencias, en cuanto que proyecta su sombra sobre multitud de aspectos del texto constitucional y muy especialmente sobre el contenido de los derechos y deberes de carácter socio-económico. Dicha fórmula, aunque ha sido utilizada para referirse a contenidos distintos y ha servido para condensar muy diversas lecturas de la cuestión social ${ }^{1}$, lo cierto es que ha conseguido caracterizar efectivamente el constitucionalismo moderno respecto de su predecesor decimonónico. Y desde los orígenes mismos del concepto, existe una íntima vinculación entre el Estado social y el mundo del trabajo. Y resulta evidente que el inmigrante irregular típico no es otra cosa que un trabajador que pretende ejercer como tal en un país extranjero.

Conviene recordar que la primera teorización del Estado social — protagonizada por Louis Blanc en la revolución de 1848_-, surgió vinculada a la idea del derecho al trabajo, considerado como derecho fundamental. Y que la materialización de esta idea de Estado social conlleva la consagración con rango constitucional de los elementos estructurales del derecho del trabajo, una rama del ordenamiento jurídico de naturaleza tuitiva, surgida precisamente para la protección de la población laboral dependiente, uno de los sectores sociales más débiles dentro de un Estado que pretende remover las desigualdades más

${ }^{1}$ GonzÁlez Moreno, B.: El Estado social. Naturaleza juridica y estructura de los derechos sociales, Madrid, 2002, p. 36. 
graves que se dan en la sociedad. De esta forma, se convierte en uno de los objetivos básicos del Estado social «la extensión del pensamiento del Estado de Derecho material al orden del trabajo y de los bienes» ${ }^{2}$.

Como es sabido, esa caracterización social del Estado se recoge expresamente en el artículo uno de nuestra Constitución y se desarrolla ulteriormente a lo largo del texto, teniendo su principal expresión en el art 9.2, pero también en el Capítulo III del Título I ( De los principios rectores de la política social y económica») y en el Título VII, relativo a Economía y Hacienda; pero la virtualidad del Estado social no se limita a estos preceptos, sino que afecta a la generalidad del ámbito constitucional y especialmente al entramado de los derechos y deberes constitucionales.

Respecto de los derechos fundamentales, se puede afirmar que el Estado social va a suponer un cambio cualitativo en su articulación, tanto en lo que respecta a su dimensión individual, como a la institucional. Así, desde la perspectiva subjetiva, esta transformación implica un cambio del estatuto del ciudadano, que no debe ser ya sólo una persona integrada política y jurídicamente en un país, sino también económica, social y culturalmente; mientras que, en su dimensión institucional, implica un cambio del estatuto jurídico-político del poder público, que, de ser básicamente vigilante y represor, pasa a ser ordenador, conformador de la sociedad ${ }^{3}$.

Es cierto que la doctrina y la jurisprudencia mayoritarias consideran que de dicha fórmula no se pueden deducir pretensiones jurídicas inmediatas por parte de los ciudadanos, pero ello no significa que carezca de trascendencia o que se limite a ser una apelación con virtualidad limitada al ámbito infraconstitucional. Reconocer que la virtualidad práctica de los derechos sociales está profundamente condicionada por el sistema económico y en concreto, por las disponibilidades financieras, no puede implicar de ninguna forma la afirmación del nulo carácter vinculante de los derechos fundamentales sociales ${ }^{4}$, sino, al revés, debe conllevar exigencias añadidas para los poderes públicos en materia presupuestaria 5 .

2 Heller, H.: «Rechstaat...», citado en PÉREz LuÑo, Derechos humanos, Estado de Derecho y Constitución, Madrid, 1991, p. 224.

3 Torres del Moral, A.: Principios de Derecho Constitucional, Madrid, 1998, p. 47.

4 Gomes Canothilho, J. J.: «Metodología fuzzy y camaleones normativos en la problemática actual de los derechos económicos, sociales y culturales», en Rev. Derechos y Libertades, n. ${ }^{\circ}$ 6, 1998 , p. 45.

5 Balaguer, F.: «El Estado social y democrático de derecho. Significado, alcance y vinculación de la cláusula del Estado social», en VV. AA. (MONEREO dir.): Comentario a la Constitución socio-económica de España, Granada, 2002, p. 101. 
En todo caso y dentro del ámbito jurídico, la fórmula del Estado social posee una indiscutible eficacia práctica en dicho nivel infraconstitucional ${ }^{6}$; y no sólo como criterio de orientación de la actividad de los poderes públicos, sino también como referente para la interpretación de las normas de rango ordinario. Pero es que además, la fórmula despliega también cierta eficacia en el propio ámbito constitucional, como criterio hermenéutico del resto de los preceptos constitucionales y en concreto, de los derechos fundamentales. Y lo hace especialmente respecto de los derechos estructuralmente conexos al Estado social (derechos sociales), sobre los cuales opera una legitimación en sede constitucional de los intereses vinculados a determinados sectores sociales, tal y como afirma expresamente el Tribunal Constitucional cuando dice que «la idea del Estado social y democrático de Derecho establecido por el art. 1.1 de la Constitución (...) entre otras significaciones tiene la de legitimar medios de defensa a los intereses de grupos y estratos de la población socialmente dependientes» ${ }^{7}$.

De hecho, el Tribunal Constitucional ha recurrido frecuentemente a la cláusula del Estado social, de la cual ha deducido consecuencias en absoluto irrelevantes en diversos aspectos relativos a los derechos de los trabajadores ${ }^{8}$. En todo caso y al margen de la eficacia que se le quiera reconocer a la fórmula del Estado social en el ámbito constitucional, queda fuera de toda duda su plena eficacia como criterio delimitador de la legislación ordinaria, habilitando el correspondiente control por parte de la justicia constitucional, que debe apreciar si las finalidades que persiguen las normas se adecuan no sólo a los derechos constitucionales concretos, sino también a la definición social del Estado?. Y como es de sobra sabido, la jurisprudencia constitucional está desempeñando en España una labor decisiva en la concreción de los derechos de los extranjeros.

${ }^{6}$ No se deben entender los argumentos a favor de las consecuencias jurídicas de la proclamación constitucional más allá de sus límites naturales, en el sentido de obviar los problemas que se plantean entre «normatividad» y «facticidad» de la norma y que tienen una trascendencia específica en el ámbito de los derechos sociales.

7 STC n. ${ }^{\circ}$ 11/1981, de 8 de abril, B.O.E. n. ${ }^{\circ}$ 99/1981, de 25 de abril, FJ 9.

${ }^{8}$ Como la diferencia cualitativa entre la huelga y el conflicto colectivo de los empresarios (STC n. ${ }^{\circ}$ 11/1981), el concepto de «mantenimiento de las conquistas sociales ya conseguidas» (81/1992), la justificación de algunas desigualdades entre empresarios y trabajadores impuestas por el derecho laboral (11/1981), la compatibilidad de pensiones (19/1982), etc.

${ }^{9}$ En Tribunal Constitucional lo ha reconocido implícitamente al afirmar, en relación a las finalidades del Estatuto de los Trabajadores, que son «... finalidades que en sí mismas no pueden calificarse de contrarias a la Constitución, en cuanto conecta......con las características del Estado Social de Derecho (art. 1), en el que pueden incluirse sin violencia los fines a que responde la regulación legal». 
Además, la Constitución no sólo define al Estado como social, sino que contiene un mandato expreso de igualdad efectiva en su artículo 9.2.: "Corresponde a los poderes públicos promover las condiciones para que la libertad y la igualdad del individuo y de los grupos en que se integra sean reales y efectivas; remover los obstáculos que impidan o dificulten su plenitud y facilitar la participación de todos los ciudadanos en la vida política, económica, cultural y social». Este mandato es la consecuencia que se deriva necesariamente de la idea de que el Estado social no es neutral ante la realidad social, como pretendía serlo el Estado liberal, por lo que su criterio de igualdad no es sólo el de la igualdad jurídica $^{10}$, sino también el de la igualdad efectiva, con el que aquella se debe armonizar; de forma que el Estado queda impelido a intervenir ante las desigualdades sociales, al objeto de corregirlas. Pero, ¿cual es el contenido concreto de este concepto de «igualdad efectiva» dirigido a la totalidad de los poderes públicos y que como se verá más adelante, afecta también a las actuaciones de estos poderes respecto de los inmigrantes irregulares? En primer lugar, es evidente que no se trata de una igualdad formal o jurídica, sino vinculada a la idea de Estado social, tal y como reconoce el Tribunal Constitucional: «con esta disposición se está superando el más limitado ámbito de actuación de una igualdad meramente formal y propugnando un significado del principio de igualdad acorde con la definición del art. 1, que constituye a España como un Estado democrático y social de Derecho» ${ }^{11}$.

Cuestión bien distinta es la del margen de apreciación que, al respecto, se debe reconocer a las mayorías parlamentarias coyunturales para interpretar ese mandato, en atención al carácter abierto de la norma constitucional; margen en virtud del cual estas mayorías no pueden ser suplantadas por la jurisdicción en cuanto a criterios de oportunidad de la ley. Esta circunstancia debe ser tenida en consideración especialmente en el caso de un mandato como el de la igualdad que admite interpretaciones bien distintas en cuanto a los instrumentos idóneos para hacerla efectiva. Pero el Tribunal Constitucional debe retener, sin duda, el control, en última instancia, de los mínimos de razonabilidad y proporcionalidad de la norma, como ha venido haciendo y en concreto, en este ámbito.

¿Afectan la definición social del estado del artículo 1 C.E. y el mandato de igualdad efectiva del artículo 9.2 a los extranjeros y en concreto a los inmigran-

${ }^{10}$ Que tiene su reconocimiento en el art 14: «Los españoles son iguales ante la ley, sin que pueda prevalecer discriminación alguna por razón de nacimiento, raza, sexo, religión, opinión o cualquier otra condición o circunstancia personal o social».

${ }^{11}$ STC 3/1983, de 25 de enero, BOE 41/1983 de 17 de febrero, FJ 3. 
tes irregulares? Sin duda. En primer lugar porque si la propia naturaleza del Estado es social, siempre que el Estado posea jurisdicción para intervenir, deberá intervenir actuando de acuerdo con la naturaleza que le ha atribuido la ley fundamental. El Estado no puede obviar esas exigencias constitucionales por el hecho de que quienes se hayan sujetos a su jurisdicción sean extranjeros, ni siquiera por el hecho de que sean extranjeros en situación irregular. El mandato del art. 9.2 es explícito al respecto, al referir la exigencia de igualdad no a los españoles, sino a los individuos y a los grupos en que se integran, dejando la expresión de "ciudadanos» para el inciso final del precepto, el referente a la participación en la vida política, económica, cultural y social. Luego, aunque la participación se acota a los ciudadanos, la igualdad se exige respecto de todos los individuos y grupos sociales que pueden ser destinatarios de la acción de los poderes públicos.

Además, uno de los ámbitos fundamentales sobre los que se proyecta tanto la definición social del Estado del art.1, como el mandato de igualdad efectiva del art. 9.2 CE es el de la relación laboral, ya que existe en el trabajo subordinado una desigualdad originaria de status entre el trabajador y el empresario y la ley debe corregir esa desigualdad; y ese es precisamente el objetivo para el que surgió una rama del Derecho, el Derecho laboral, que posee un carácter específico que lo distancia del derecho de contratos, frente al cual «se constituye como un ordenamiento compensador e igualador, en orden a la corrección, al menos parcialmente, de las desigualdades fundamentales» ${ }^{12}$. Y además, el contenido básico de estas normas protectoras adquiere en el Estado social rango constitucional, conformando una suerte de Derecho constitucional del trabajo.

Una Constitución que exige que el Estado actúe siempre atendiendo a su función social, que impele a los poderes públicos a corregir las desigualdades sociales y que eleva al máximo rango un aparato normativo dirigido precisamente a proteger el trabajo subordinado, no puede ignorar precisamente al que es sin lugar a dudas el colectivo social más frágil. Y no puede ignorarlo con la excusa de la no pertenencia a la comunidad, ya que se trata de personas sometidas a la jurisdicción de ese Estado y por tanto, destinatarias de sus normas. Y respecto de estas personas, el Estado no puede ignorar las exigencias constitucionales.

Es evidente que el mandato de igualdad ante la ley del artículo 14 C.E. se halla acotado para los españoles y determina para ellos unos contenidos específicos, pero ello no es argumento suficiente para obviar el hecho de que este mandato de igualdad formal coexiste con el mandato de igualdad material del ar-

12 FJ 10 de la STC 3/1983, cit.. 
tículo 9.2, que va dirigido a todos los individuos y grupos a los que puede afectar la acción del Estado, un Estado que se define constitucionalmente como social y que, por tanto, no puede actuar prescindiendo de esa naturaleza respecto de ninguno de los destinatarios de sus normas.

\section{LA LIBERTAD DE MIGRAR COMO DERECHO HUMANO Y COMO DERECHO CONSTITUCIONAL}

Frecuentemente la doctrina jurídica aborda el fenómeno de la inmigración irregular desde una perspectiva fragmentaria y reglamentista. Para conjurar este riesgo, conviene tener en cuenta todas las facetas implicadas y todos los bienes jurídicos en juego y abordarlos desde una visión integral del Derecho, que pondere las consideraciones de legalidad ordinaria con las de legalidad constitucional e internacional.

El inmigrante irregular es una persona que ha abandonado su país para acceder a otro sin haber obtenido la autorización administrativa que para ello es requerida por la legislación del país receptor o habiendo perdido la que previamente poseía. Intentemos analizar por separado las distintas circunstancias que concurren en el fenómeno y sus implicaciones jurídicas.

La primera cuestión a tener en cuenta es que el inmigrante ha abandonado el país del que es nacional. $\mathrm{Al}$ margen de las previsiones legales o administrativas del país de origen, desde la perspectiva del Derecho internacional, al tomar esa decisión de abandonar su país y ponerla en práctica, dicha persona esta ejercitando un derecho humano, el derecho a emigrar. Por lo que se refiere a su conformación teórica, este derecho a emigrar es prácticamente tan antiguo como el propio Derecho internacional, desde que Francisco de Vitoria invocara el «titulus naturalis societatis et communicationis», la facultad de cualquiera para emigrar y entablar lazos con otros pueblos, siempre que fuera con intenciones pacíficas. En la actualidad, se ha considerado que este derecho a emigrar no es sino el corolario del derecho a la libertad de movimiento o circulación ${ }^{13}$, es decir, la libertad de movimiento ejercida fuera de las fronteras nacionales. Y esto no sólo es así desde la perspectiva del derecho internacional, sino que, en mi opinión, lo es también desde la del derecho español.

Desde la legalidad internacional, el derecho a abandonar el propio país y emigrar es un derecho fundamental e incontrovertible. Se halla recogido expresa-

13 Cancado Trindade, A.: www.corteidh.or.cr/docs/medidas/votos/haitianos_vse_02_cancado.doc. 
mente en el instrumento jurídico más importante de esta ${ }^{14}$, en la Declaración universal de los derechos humanos, cuyo artículo 13.2 establece que "Toda persona tiene derecho a salir de cualquier país, incluso del propio, y a regresar a su país». Igualmente, el Pacto Internacional de Derechos Civiles y Políticos (1966) afirma en su artículo 12.2 que «Toda persona tendrá derecho a salir libremente de cualquier país, incluso del propio», añadiendo en el 12.4 que «Nadie podrá ser arbitrariamente privado del derecho a entrar en su propio país».

Por lo que se refiere al derecho español, la Constitución no reconoce expresamente el derecho a emigrar con ese nombre, aunque sí el derecho de los españoles a abandonar el país; al contrario de lo que sucedía con la Constitución de 1931, que afirmaba expresamente que «El derecho a emigrar o inmigrar queda reconocido y no está sujeto a más limitaciones que las que la ley establezca»; y al contrario también de lo que sucede con otras constituciones de nuestro entorno, como la portuguesa ${ }^{15}$ o la italiana ${ }^{16}$. En cambio, si se afirma expresamente ese derecho de los nacionales a entrar y salir del país, incluido en la libertad de movimiento. Dichos derechos vienen tipificados en el artículo 19, que proclama que "Los españoles tienen derecho a elegir libremente su residencia y a circular por el territorio nacional. Asimismo, tienen derecho a entrar y salir libremente de España en los términos que la ley establezca. Este derecho no podrá ser limitado por motivos políticos o ideológicos».

En resumen, el derecho de circulación y residencia y su corolario, el derecho a emigrar y retornar, se reconoce a los españoles exclusivamente. ¿Significa esto que en nuestro derecho los extranjeros carecen de tales libertades o si las poseen es únicamente por atribución legal? En mi opinión, no. El propio Tribunal Constitucional, aunque tiene una visión muy limitada de la libre circulación internacional, ha afirmado que «la inexistencia de declaración constitucional que proclame directamente la libertad de circulación de las personas que no ostentan la nacionalidad española no es argumento bastante para considerar resuelto el problema ${ }^{17}$, ya que el artículo 13 «solamente reserva a los españoles la titularidad de los derechos reconocidos en el artículo $23 \mathrm{CE}{ }^{18}$.

${ }^{14} \mathrm{Y}$ se halla reconocido precisamente compartiendo artículo con la libertad de movimiento que proclama el párrafo primero del art 13: «Toda persona tiene el derecho a la libertad de movimiento y residencia dentro de las fronteras de cada Estado".

15 Art. 44, párrafo segundo: «Se garantiza a todos el derecho a emigrar o salir del territorio nacional, así como el derecho de regreso».

16 Art. 35: «La República.... reconoce la libertad de emigración, salvando las obligaciones establecidas por la ley en pro del interés general...».

17 STC n. ${ }^{\circ}$ 115/1987, de 7 de julio, BOE n. ${ }^{\circ}$ 180/1987, de 29 de julio, FJ 2.

18 Idem. 
El alto tribunal reconoce por tanto que el silencio del art. 19 respecto de los extranjeros, no puede interpretarse, en ningún caso, «a sensu contrario», como su negación. Considero que además, negarlos constituiría una conculcación de derechos universalmente reconocidos y ya sabemos que no puede haber una colisión frontal de la Constitución con la legalidad internacional en materia de derechos humanos. Para eso está el mandato específico del artículo 10.2, que obliga a interpretar los derechos de acuerdo con la legalidad internacional y en concreto, con la Declaración Universal y los tratados ratificados por España, entre los cuales está el Pacto de Derechos Civiles y Políticos de 1966. Por tanto, la libertad de circulación y el derecho a migrar del artículo 19 deben interpretarse de acuerdo con dichas normas, de forma que resultan extensivos a los extranjeros, aunque ello no significa que lo sean necesariamente en las mismas condiciones que para los nacionales. En todo caso, sí parece claro que el derecho español debe reconocer a los extranjeros esos derechos como mínimo con el contenido indisponible que les atribuyen las mencionadas normas internacionales.

Pero, aunque no existiera el mandato específico del artículo 10.2, considero que la propia naturaleza del derecho a la libre circulación y a emigrar no es la de un derecho exclusivamente de ciudadanía, sino de un derecho humano fundamental, de una libertad intrínsecamente vinculada a la dignidad personal y al libre desarrollo de la personalidad que proclama el artículo 10.1 de nuestra Constitución. Porque el ser humano puede necesitar en algunas ocasiones huir de un entorno que le impide su desarrollo personal y el ejercicio de sus derechos y establecerse en un lugar donde estos estén garantizados. Y dicho precepto tiene inequívocamente como destinatarios a todas las personas y no únicamente a los españoles.

Desde dicha perspectiva de vinculación con el desarrollo de la personalidad, el derecho a emigrar, además de una expresión de la libertad de movimiento, puede considerarse también como un derecho de naturaleza instrumental, un derecho cuyo ejercicio puede habilitar el ejercicio de otros derechos también fundamentales y vinculados a la dignidad humana.

Sin embargo, esta opinión no es pacífica en doctrina y no todos admiten dicha vinculación. El propio Tribunal Constitucional la ha rechazado expresamente en alguna ocasión, afirmando que «la libertad de circulación a través de las fronteras del Estado y el concomitante derecho a residir dentro de ellas, no son derechos imprescindibles para la garantía de la dignidad humana (...), ni por consiguiente pertenecen a todas las personas en cuanto tales al margen de su condición de ciudadano» ${ }^{19}$.

19 STC n. ${ }^{\circ}$ 94/1993, de 22 de marzo, B.O.E. n. ${ }^{\circ}$ 100/1993, de 27 de abril, FJ 3. 
Pero es que, incluso en el caso de que no se admitiera la vinculación de este derecho a la dignidad humana, lo cierto es que la libertad de circulación y el derecho a emigrar constituyen un derecho reconocido en el artículo 19 de la Constitución española y por tanto, un derecho que pertenece a su Título I; y como ha venido proclamando reiteradamente el Tribunal Constitucional, todos los derechos del Título I, con excepción de los derechos políticos del artículo 23, pueden corresponder también a los extranjeros, aunque no necesariamente en condiciones de igualdad con los españoles, condiciones de igualdad que si se atribuyen en cambio al disfrute, por unos y otros, de los derechos vinculados a la dignidad ${ }^{20}$. Por lo tanto y siguiendo al Tribunal, de la inexistencia de una declaración constitucional que proclame directamente la libertad de circulación de las personas que no ostentan la nacionalidad española no puede deducirse que carezcan de este derecho y en consecuencia, al estar excluidos únicamente de los derechos del art. 23, «resulta claro que los extranjeros pueden ser titulares de los derechos a residir y a desplazarse libremente que recoge la Constitución en su art. $19 \|^{21}$.

Y resulta evidente también que el Estado puede regular el acceso a su territorio de ciudadanos extranjeros; pero cuando lo hace, no actúa de forma discrecional, como ha reconocido el propio tribunal, sino con una libertad limi$\operatorname{tada}^{22}$. ¿Cuáles son los límites al arbitrio del legislador? La respuesta no es sencilla, ya que depende de que se considere o no un derecho vinculado a la dignidad humana. Si no se considera como tal, entonces el límite de la discrecionalidad estaría en el respeto a la Declaración Universal de derechos Humanos y a los tratados internacionales suscritos por España. Y en concreto, las Leyes y tratados que regulen la circulación de extranjeros en España deben respetar el grado, limitado pero cierto, de libertad que reconocen los artículos $12^{23}$ y

20 «Los extranjeros gozan en España de las libertades públicas que garantiza el Título I de la Constitución, aún cuando sea en los términos que establezcan los tratados y la ley». STC n. ${ }^{\circ}$ 94/1993, cit., FJ 2 (confirmando doctrina de las sentencias 107/1984, 99/1985, 115/1987, etc.

${ }^{21}$ Idem.

22 «La libertad del legislador al configurar los derechos de los nacionales de los distintos Estados, en cuanto a su entrada y permanencia en España, es sin duda alguna amplia. Pero no es en modo alguno, absoluta...», FJ 2, de la STC 115/1987, cit.

${ }^{23}$ Artículo 12: 1. "Toda persona que se halle legalmente en el territorio de un Estado tendrá derecho a circular libremente por él y a escoger libremente en él su residencia. 2. Toda persona tendrá derecho a salir libremente de cualquier país, incluso del propio. 3. Los derechos antes mencionados no podrán ser objeto de restricciones salvo cuando éstas se hallen previstas en la ley, sean necesarias para proteger la seguridad nacional, el orden público, la salud o la moral públicas o los derechos y libertades de terceros, y sean compatibles con los demás derechos reconocidos en el presente Pacto. 4. Nadie podrá ser arbitrariamente privado del derecho a entrar en su propio pais». 
$13^{24}$ del Pacto Internacional a todas las personas que se hallan legalmente en el territorio español ${ }^{25}$.

En resumen, se puede afirmar que tanto en el derecho internacional como en el derecho español, se protege el derecho a emigrar. En segundo lugar, constatamos que el derecho español reconoce esta libertad tanto a los españoles como a los extranjeros, aunque, si se sigue la idea del Tribunal Constitucional de que no se trata de un derecho vinculado a la dignidad, entonces no tendría necesariamente el mismo contenido para unos y otros. En todo caso, además del contenido esencial que el art. 23 atribuye al derecho a migrar para los españoles, también el contenido que posee el derecho en los tratados internacionales mencionados supone un límite de la discrecionalidad del legislador ordinario. Un límite que no opera en este caso sólo respecto de los nacionales, sino también de los extranjeros.

\section{DERECHO A EMIGRAR, DERECHO A INMIGRAR Y SOBERANÍA NACIONAL.}

Como ya se ha mencionado, resulta pacífica en doctrina la admisión del derecho fundamental a abandonar el propio país. Sin embargo, no sucede lo mismo con el derecho a entrar en un país. Muchos autores consideran que no se puede impedir a una persona que salga de su país, pero para ellos, esa misma persona carecería del derecho a exigir la admisión en otro con carácter general. De lo que no cabe ninguna duda es que los nacionales de un país tienen el derecho fundamental a entrar en su propio país y a salir de él, derecho del cual nadie puede ser privado arbitrariamente, como establece expresamente el Pacto internacional de derechos civiles y políticos ${ }^{26}$ y como ha afirmado el Tribunal constitucional, para quien el derecho a ser aceptado por el propio Estado constituye no sólo un derecho fundamental del nacional, sino también uno de los «elementos esenciales de la nacionalidad» ${ }^{27}$. De hecho, el Tribunal va más allá en

${ }^{24}$ Artículo 13: "El extranjero que se halle legalmente en el territorio de un Estado parte en el presente Pacto sólo podrá ser expulsado de él en cumplimiento de una decisión adoptada conforme a la ley; $y$, a menos que razones imperiosas de seguridad nacional se opongan a ello, se permitirá a tal extranjero exponer las razones que lo asistan en contra de su expulsión, asi como someter su caso a revisión ante la autoridad competente o bien ante la persona o personas designadas especialmente por dicha autoridad competente, $y$ hacerse representar con tal fin ante ellas».

25 FJ 2 de la STC 115/1987, cit.

26 Arts. 12.2 y 12.4 .

27 STC n. ${ }^{\circ}$ 72/2005, de 4 de abril, BOE n. ${ }^{\circ}$ 111/2005, de 10 de mayo, FJ 6. 
sus conclusiones y considera que, al tratarse de un atributo de la nacionalidad, los extranjeros están excluidos de dicho derecho, lo que constituye en su opinión una de las diferencias básicas entre el estatuto personal del nacional y el del extranjero $^{28}$. La razón de dicha exclusión no reside, siguiendo el criterio del Tribunal, en el hecho de que el artículo 19 CE mencione únicamente a los españoles como titulares del derecho, ya que esto no significa automáticamente que se excluya la titularidad por parte de extranjeros, puesto que hay derechos que no se atribuyen explícitamente a estos, pero que les pueden ser atribuidos, en virtud del art. 13.1, por la circunstancia de hallarse estos en territorio español, circunstancia que actúa como "presupuesto de extensión de derechos»" ${ }^{29}$. Sin embargo, no es finalidad de este precepto «convertir en derecho la eventual expectativa de entrar en España de todos los extranjeros que están fuera de nuestro país y que se presenten en nuestras fronteras» ${ }^{30}$. En resumen, lo que el tribunal plantea de una forma tan enfática es que no se puede alegar para entrar en España un derecho que en todo caso nuestras leyes sólo podrían atribuir a quien ya esta dentro de España.

Personalmente, discrepo de dicha afirmación y discrepo también del planteamiento que la subyace. En mi opinión, el problema no reside en pretender convertir en derecho fundamental la eventual expectativa de entrar en España de todos los extranjeros. El problema jurídico que se plantea es que tanto la legalidad internacional como nuestra legalidad constitucional reconocen el derecho fundamental de toda persona a abandonar un país. Luego, España, como por otra parte, hacen el resto de los Estados respetuosos de la legalidad internacional, está atribuyendo un derecho a la persona que desea emigrar o se ve forzada a ello y lo esta haciendo en forma solidaria con todos los demás miembros de la comunidad internacional. Un derecho que si es tal, no es una mera expectativa, sino que posee virtualidad jurídica y resulta por tanto exigible. Y ello conlleva necesariamente algún tipo de exigencias para quien hace el reconocimiento del derecho, si bien se podría alegar que, al tratarse de un reconocimiento que no se hace con carácter individual por parte de un Estado, sino colectivamente por parte de todos ellos, conllevaría una suerte de responsabilidad solidaria en cuanto a la prestación del derecho.

En resumen, considero que el problema jurídico concreto que se plantea aquí no consistiría en si todos los extranjeros poseen derecho a entrar en España, lo cual constituye una cuestión más abstracta y filosófica, sino en saber qué obli-
${ }^{28}$ Idem.
29 Idem.
30 Idem. 
gaciones comporta para los Estados y en concreto para el Estado español, el reconocimiento a todas la personas del derecho a abandonar su país. Y más en concreto, el hecho de cuales son las exigencias en cuanto al trato que debe dispensar España al extranjero que, en el ejercicio de su derecho a emigrar reconocido por las normas internacionales, accede a territorio español y por lo tanto, se halla bajo la jurisdicción de autoridades españolas. ¿La regulación de la autorización de permanencia es absolutamente discrecional para el legislador y en tal caso, cual es la virtualidad del reconocimiento supralegal del derecho? Se trata sin duda de una pregunta bastante compleja y antes de esbozar un intento de respuesta considero necesario examinar, si bien someramente, los argumentos que se esgrimen a favor de la discrecionalidad.

Ya hemos visto que el Tribunal Constitucional se alinea al respecto con la doctrina más tradicional y lo hace basándose en el criterio más convencional, el de la soberanía nacional, de forma que sus planteamientos resumen de alguna manera los de dicho sector. Así, afirma que el derecho a entrar en España, con el carácter de fundamental, sólo corresponde a los españoles y no a los extranje$\operatorname{ros}^{31}$, aunque considera que ello no debe entenderse en el sentido de que los extranjeros carezcan totalmente de derecho a entrar en España, sino sólo que se trata de un derecho cuyo otorgamiento puede someter el legislador al cumplimiento de determinados requisitos legales ${ }^{32}$.

Desde esta perspectiva, el Estado no estaría obligado a aceptar el acceso a su territorio de personas procedentes de otros territorios por principio y salvo en determinados casos excepcionales, casos que estarían excluidos del régimen general para integrarse en el régimen específico del asilo. Pero respecto de todos los demás, la decisión al respecto resultaría libre y sería al derecho nacional al que correspondería fijar los criterios de admisión de ciudadanos extranjeros, de forma que estos no tendrían un derecho a exigir la entrada o, al menos, no lo tendrían de una naturaleza superior o previa al que les confiriera la legalidad ordinaria. En resumen, lo que el Tribunal defiende es que el nacional no puede ser privado arbitrariamente de su derecho a entrar y salir de su país, pero en cambio sí se puede prohibir la entrada de extranjeros arbitrariamente a un país.

Siguiendo estos planteamientos de la doctrina mayoritaria y que hace suyos el Tribunal Constitucional, se plantea una contradicción: ¿Cómo es posible afirmar que el derecho a abandonar un país es un derecho fundamental de todo ser humano y a la vez defender que todos los Estados pueden denegar ar-

31 FJ 7 de la STC 72/2005, cit.

32 STC cit., FJ 8. 
bitrariamente la entrada de extranjeros? ¿Cómo puede una persona tener el derecho a abandonar un país si no posee el derecho a entrar en ningún otro?

La justificación teórica de esta aparente incongruencia radica, para la mayoría de la doctrina, en el mencionado principio de la soberanía nacional. Este principio es todavía hoy bastante pacífico en el derecho internacional, a pesar de las mermas que el concepto tradicional de soberanía ha experimentado en los últimos tiempos como consecuencia del proceso de globalización. Y a pesar de que ni siquiera el concepto tradicional de soberanía ha sido un concepto ilimitado, sino sólo tendencialmente ilimitado, ya que desde antiguo la doctrina del derecho internacional ha predicado la sumisión del derecho nacional al derecho de gentes o a los «principios generales de derecho reconocidos por las naciones civilizadas»" ${ }^{33}$. Y esa «limitación» de la soberanía planteada por la doctrina internacionalista cobra carta de naturaleza y comienza a adquirir efectividad a raíz del sistema de las Naciones Unidas y muy especialmente en lo que atañe al ámbito de los derechos humanos, cuyo régimen supone una importante quiebra del concepto tradicional de soberanía nacional.

Sin embargo, aún hoy en día se sigue sosteniendo que la soberanía conlleva el derecho de la comunidad política a establecer los criterios de admisión de extranjeros en el territorio nacional. ¿Es esto así? Incluso obviando las limitaciones que en la actualidad se le reconocen al principio de la soberanía, de lo que no parece que haya dudas es de que el Estado está legitimado para establecer los criterios de pertenencia a la comunidad nacional. Y tampoco de que, siendo el territorio uno de los elementos constitutivos de la soberanía, corresponden a dicha comunidad nacional las decisiones básicas a adoptar dentro de las fronteras que lo definen.

En este sentido, la plenitud del ejercicio de los derechos políticos se reserva con carácter general a los nacionales, como sucede en nuestro ordenamiento jurídico. Lo cual tampoco supone que los extranjeros carezcan totalmente de derechos políticos, aunque sí en líneas generales del derecho de sufragio activo y pasivo y del de acceso a cargos y función pública. Debe tenerse en cuenta además que la exclusión de este derecho de sufragio, considerado tradicionalmente como traducción directa de la soberanía nacional, está siendo objeto de crítica por parte de importantes sectores doctrinales y ha empezado incluso a sufrir sus primeras fisuras, hasta el punto de que la primera reforma de la Constitución española de 1978 fue exigida precisamente para introducir una excepción a dicho principio, aunque lo fuera exclusivamente a favor de determinados ciudadanos extranjeros, concretamente los pertenecientes a otros Es-

33 Art. 38 del Estatuto del Tribunal Internacional de Justicia 
tados miembros de la Comunidad Europea y sólo para las elecciones municipales. En relación a dicho proceso, el Tribunal constitucional ha mantenido que el tradicional binomio entre el estatuto personal del nacional y el del extranjero, va siendo progresivamente objeto de parcial superación en el marco de una naciente ciudadanía europea ${ }^{34}$.

En todo caso, se trata de la excepción a la regla y no de la regla en sí. La regla sigue siendo la de la limitación de los derechos políticos a los extranjeros y la mayoría de la doctrina sigue aún identificando soberanía nacional con exclusión de los extranjeros del proceso decisorio nacional. Y es probable que haga falta aún bastante tiempo para que en dicho esquema vayan profundizando las cuñas mencionadas y vaya abriéndose paso la idea de que quienes desarrollan su vida de forma relativamente estable en un país y son destinatarios de su ordenamiento jurídico, no deben ser totalmente excluidos del proceso democrático de este ${ }^{35}$.

Sin embargo y dejando aparcado dicho debate e incluso admitiendo como hipótesis de trabajo la legitimidad de que se excluya a los extranjeros del proceso decisorio interno, considero que ni el derecho a definir las condiciones de acceso a la comunidad política, ni el criterio de la jurisdicción sobre un territorio, implican necesariamente una especie de propiedad ilimitada e incondicionada sobre dicho territorio; ni mucho menos implican la negación a los no miembros de esa comunidad de la libertad de circulación a través de él. De hecho, aunque se entendiera la soberanía sobre el territorio en términos de propiedad e incluso bajo criterios decimonónicos de propiedad, lo cierto es que la propiedad no conlleva siempre y necesariamente la exclusión de cualquier uso por parte de los no propietarios. En resumen, creo que siendo el derecho a emigrar un derecho humano fundamental y no siendo el uso privativo del territorio una condición intrínseca de la soberanía, no se puede derivar necesariamente del principio de soberanía el carácter absolutamente discrecional del acceso de los extranjeros al territorio nacional.

A esa misma conclusión llegaremos también por reducción al absurdo de la hipótesis contraria. Porque, si todos los países son soberanos y son igualmente soberanos entre ellos, todos ellos tendrán la misma discrecionalidad para decidir

${ }^{34}$ Declaración del TC de 1 de julio de 1992, FJ 3 a).

35 Siguiendo a Eliseo Aja y Laura Díez Bueso, podemos agrupar en tres las razones que aconsejan la participación política de los inmigrantes: en primer lugar, que resulta necesaria para impulsar los derechos civiles y sociales de ese colectivo; en segundo, que favorece su integración en la sociedad en la que viven; y en tercero, que es una exigencia del propio proceso democrático, que se beneficiaría de inclusión en los procedimientos de elaboración de las normas de quienes van a ser sus destinatarios (http://www.lafactoriaweb.com/articulos/aja10.htm). 
la admisión en sus territorios de extranjeros. Y si todos deciden no admitirlos, para lo cual son igualmente libres, entonces no existiría un derecho humano a abandonar el propio país. No se trataría de un auténtico derecho sino de una simple aspiración, ya que su virtualidad estaría condicionada a una concesión que deberían hacer los demás países.

En conclusión, podemos afirmar que cualquier reconocimiento del derecho a salir de un país conlleva el reconocimiento de que existe algún país al que se puede entrar ${ }^{36}$ y que dicha posibilidad no queda por tanto al arbitrio de las autoridades del país receptor, ya que si la admisión por un país en concreto fuera totalmente discrecional, sería igualmente discrecional la admisión por todos y cada uno de los demás países, igualmente soberanos; y por tanto, ningún país tendría obligación de admitir al extranjero, de forma que no existiendo la posibilidad de exigir la entrada en ningún país, no existiría el derecho a salir del propio. En consecuencia, considero que el reconocimiento del derecho a abandonar un país como derecho humano inalienable conlleva el reconocimiento de que la entrada en otro no constituye una decisión sometida a criterios de absoluta discrecionalidad.

De las anteriores reflexiones no deben extraerse más consecuencias de las necesarias. No se pretende negar que el Estado carezca de competencia para denegar la entrada de ciudadanos extranjeros en territorio nacional, sino sólo que dicha competencia no es discrecional. Sería absurdo pretender que el Estado carece de legitimación para restringir en ningún caso la entrada de extranjeros. Lo único que se pretende afirmar es que la tipificación actual del principio de soberanía nacional no puede interpretarse en el sentido de considerar las fronteras nacionales como límites absolutos a la libertad de circulación. Y de esta libertad forma parte la libertad de migrar como derecho inalienable; un derecho que se niega si su virtualidad depende de una autorización discrecional de la Administración del país de destino.

\section{RESTRICCIONES ADMISIBLES AL DERECHO A INMIGRAR}

Sin embargo, como se ha dicho, no existe contradicción entre afirmar dicho derecho, por una parte y reconocer, por otra, que el Estado puede denegar en algunos casos la entrada de ciudadanos extranjeros en territorio nacional. Y no existe contradicción porque la libertad de circulación no es un derecho ilimita-

36 PeÑA, L.: «El derecho del individuo a circular libremente y a escoger su residencia», en www.eroj.org/Minerva/dercircu.htm\#02. 
do, como no lo es ningún derecho. Y el bien jurídico protegido por una norma puede entrar en determinados casos en colisión con otros bienes jurídicos igualmente protegidos y ceder ante ellos. En todo caso, conviene insistir en que, si se admite el derecho, no puede admitirse una plena discrecionalidad del Estado; y conviene insistir también en que este tiene la obligación de actuar en consecuencia con el hecho de que su decisión afecta a un bien jurídico protegido; y protegido, además, tanto por el orden internacional como por el orden interno; y en ambos casos por las normas jurídicas de rango más elevado: la Declaración Universal de Derechos Humanos y nuestra ley fundamental en su título más privilegiado, el Título I relativo a los derechos. Y ese bien jurídico no es otro que la decisión de un ser humano de abandonar su país.

En resumen, se puede afirmar que sí es posible que las normas internas limiten el acceso de ciudadanos extranjeros a territorio nacional, pero que no existe arbitrio total al respecto; y que los supuestos legales de denegación sólo pueden traer su legitimación de una interpretación equilibrada y proporcionada del conjunto de bienes objeto de protección constitucional. Considero que en este sentido abundan las palabras del Tribunal Constitucional cuando, con motivo del recurso de inconstitucionalidad contra la Ley de extranjería de $1985^{37}$, dijo que la compresión de los derechos de los extranjeros "puede justificarse para la salvaguardia de otros bienes o derechos constitucionalmente protegidos ${ }^{38}$ ».

No caben por tanto dudas en cuanto a la legitimación que posee el Estado para limitar el derecho de los extranjeros a acceder al territorio español y en esa medida, a limitar su derecho a emigrar. Sin embargo, concretar en detalle cuales sean los casos en que puede ceder el derecho a migrar ante intereses superiores es una labor tremendamente compleja. Ya hemos visto en el apartado relativo a la libertad de migrar como derecho humano que el Tribunal Constitucional ha afirmado que las Leyes y tratados que regulen la circulación de extranjeros en España deben respetar las libertades que reconoce el Pacto Internacional de derechos civiles y políticos a todas las personas que se hallan legalmente en el territorio español ${ }^{39}$. Dicho Pacto contiene en sus artículos 12 y 13 una serie de derechos mínimos de los emigrantes, que podemos agrupar en tres:

- El derecho de un inmigrante a retornar a su país, derecho del cual nadie puede ser privado arbitrariamente (art. 12.4).

${ }^{37}$ Ley Orgánica 7/1985, de 1 de julio, BOE n. ${ }^{\circ}$ 158/1985, de 3 de julio.

38 FJ 4 de la STC 115/1987, cit.

39 FJ 2 de la STC 115/1987, cit. 
- El derecho del extranjero que se halle regularmente en un país a la libre circulación y residencia (art. 12.1) y la prohibición de expulsión que no siga un procedimiento legal y con ciertas garantías (art. 13).

— El derecho de toda persona a abandonar cualquier país (art. 12.2).

Sin embargo, aunque el Pacto recoge expresamente el derecho a abandonar un país, no contiene mención alguna de cuales sean las causas que legitiman la no admisión por parte de un Estado de un ciudadano extranjero que ejerce dicho derecho a emigrar.

El Tribunal Constitucional español, aunque no admite que el derecho a emigrar - y en consecuencia su componente específico de entrada y permanencia en territorio español - sea un derecho vinculado a la dignidad humana y aunque considera que se trata de un derecho de configuración legal, sin embargo tampoco llega a afirmar la discrecionalidad absoluta del Estado en la regulación de dicho acceso, sino sólo «la amplia potestad de que disponen los poderes públicos para controlar la entrada, la residencia y la expulsión de los extranjeros en su territorio» ${ }^{40}$. El tribunal considera además que esta conclusión, en el sentido de que la potestad del Estado es amplia, se ve corroborada por la jurisprudencia del Tribunal Europeo de Derechos Humanos ${ }^{41}$. Sin embargo, no parece tener en cuenta al respecto que dicho Tribunal es garante de los derechos reconocidos por los Estados partes en el Convenio europeo para la protección de los derechos humanos y de las libertades fundamentales ${ }^{42}$, cuando dicho Convenio no recoge el derecho a emigrar, derecho que sí se recoge, en cambio, en la Declaración Universal de Derechos Humanos y en el Pacto Internacional de derechos civiles y políticos; y en este último, con una tipificación bastante detallada.

En todo caso, nos interesa retener aquí que el propio Tribunal Constitucional admite que se trata de una potestad amplia, pero no ilimitada. Si no existe, por tanto, discrecionalidad absoluta, ¿cuales serían entonces los requisitos para el ejercicio legítimo, por parte del Estado, de su potestad para rechazar el acceso de inmigrantes? Ya se ha dicho que el pacto no contiene una previsión específica al respecto, pero en mi opinión, la respuesta a dicho interrogante puede obtenerse por aplicación analógica de algunos de los criterios de la propia norma y en concreto, a través de una interpretación no restrictiva de los criterios que establece el apartado 3 del artículo 12. Ese apartado establece concretamente cuales serían las

$40 \mathrm{STC}_{\text {n. }}{ }^{\circ}$ 24/2000, de 31 de enero, BOE n. ${ }^{\circ}$ 54/2000, de 3 de marzo, FJ 4.

41 SSTEDH Abdulaziz, de 28 de mayo de 1985, Berrehab, de 21 de junio de 1988, Moustaquim, de 18 de febrero de 1991, Ahmut, de 28 de noviembre de 1996, etc.

${ }^{42}$ Convenio de Roma de 4 de noviembre de 1950. 
limitaciones legítimas a dos de entre los contenidos concretos del derecho a emigrar: la libertad de circulación y de residencia de los extranjeros que se hallan regularmente en un país y el derecho que todos poseen a abandonar cualquier país. Y respecto de estos dos componentes del derecho, se establecen en dicho apartado cuales serían los requisitos que legitimarían su limitación. Se trata concretamente de tres requisitos:

1) Que las restricciones se hallen previstas en la ley.

2) Que sean necesarias para proteger la seguridad nacional, el orden público, la salud o la moral públicas o los derechos y libertades de terceros.

3) Que sean compatibles con los demás derechos reconocidos en el presente Pacto.

Pues bien; considero que estos requisitos que el Pacto exige para la restricción de los mencionados componentes del derecho pueden hacerse extensivos a los de cualquiera de los componentes de aquel. Y considero, por tanto, que dichos requisitos constituyen el límite de la discrecionalidad del Estado en la admisión de extranjeros con carácter general y en concreto en nuestro país.

De todo lo dicho con anterioridad, creo que se pueden extraer las siguientes conclusiones provisionales:

- Que todas las personas poseen un derecho a abandonar cualquier país, lo que conlleva necesariamente que el resto de países no poseen una discrecionalidad total para denegar el acceso a ellos.

- Que, por interpretación analógica del art. 12.3 del Pacto internacional de derechos civiles y políticos, debe entenderse que dicha discrecionalidad posee dos límites: uno de tipo formal, que es la reserva de ley, límite respecto del cual no cabe duda alguna en nuestro ordenamiento jurídico, en el cual dicha reserva posee incluso un carácter agravado, ya que no se trata de una reserva de ley ordinaria, sino de ley orgánica; y otro material, que consiste en que las restricciones se legitimen en una causa de riesgo para el orden público o para los derechos y libertades de ter$\operatorname{ceros}^{43}$.

43 Sobre la eficacia en España del criterio del orden público como elemento legitimador de la restricción de derechos de los extranjeros, no cabe duda, habiéndose pronunciando el Tribunal Constitucional expresamente al respecto, afirmando que es lícito que la Ley subordine el derecho de los extranjeros a residir en España al cumplimiento de determinadas condiciones, como son, entre otras, la de no estar implicados en actividades contrarias al orden público, o la de no cometer delitos de cierta gravedad, como ha sucedido en la STC n. ${ }^{\circ}$ 24/2000, ya citada (FJ 4). 
En consecuencia, considero que la legislación española en materia de extranjería posee unos condicionantes, no sólo formales, sino también de contenido, de forma que no puede basar las condiciones de admisión de extranjeros en criterios de mera oportunidad, al no ser legítimas más limitaciones que las que traigan su causa precisamente en el mantenimiento del Orden público y en la preservación de los derechos de los nacionales y residentes.

No cabe duda de que se trata de criterios muy generales y de que admiten un margen realmente amplio de interpretación. No es fácil establecer cuando la llegada masiva de extranjeros en general o la de determinados colectivos o individuos puede llegar a poner en peligro la preservación del orden público y/o los derechos de los nacionales. Corresponde sin duda al legislador, es decir, a las mayorías parlamentarias cambiantes, concretar en cada momento esos criterios, en el ejercicio de la soberanía nacional. Y dicha labor no puede ser sustituida por ningún control jurisdiccional. Pero, por otra parte, tampoco cabe duda de que el Tribunal Constitucional mantiene en última instancia el control de la adecuación de dichos preceptos legales a las previsiones constitucionales y a los tratados internacionales en la materia a los que nos remite el art. 10.2. $\mathrm{CE}^{44}$.

De hecho, el alto tribunal ya ha tenido oportunidad de controlar la legitimidad de la legislación de extranjería ${ }^{45}$ y se ha remitido expresamente a los criterios establecidos en el Pacto de derechos civiles y políticos para determinar la validez de las restricciones de los derechos de los extranjeros previstas en dicha normativa ${ }^{46}$. Sin embargo, no existe una doctrina jurisprudencial que establezca los criterios concretos de legitimidad de la restricción de entrada a los ciudadanos extranjeros. Se trata además de una cuestión que como se ha mencionado, no resulta en absoluto pacífica doctrinalmente y cuyo análisis en profundidad excede sin duda las pretensiones de este trabajo. Un trabajo en el que no voy po-

${ }^{44} \mathrm{Y}$ por supuesto, los órganos jurisdiccionales retienen el control de la interpretación y aplicación de dichas normas, y deben evitar la discrecionalidad de la acción de la Administración en un ámbito sin duda especialmente proclive a las violaciones de derechos, como es este de la extranjería.

45 Por ejemplo, en la STC n. ${ }^{\circ} 115 / 1987$, ya citada.

46 Aunque en dicha sentencia se analiza básicamente un aspecto específico del derecho, como es de la protección constitucional a los desplazamientos de los extranjeros en España y más concretamente el de si los extranjeros que residen regularmente en el país, poseen también libertad de circulación y residencia. El pronunciamiento del tribunal es favorable y afirma que «los extranjeros que, por disposición de una Ley o de un tratado, o por autorización concedida por una autoridad competente, tienen derecho a residir en España, gozan de la protección que brinda el art. $19 \mathrm{CE}$, aún cuando no sea en idénticos términos que los españoles, sino en los que determinen las Leyes y tratados a los que se remite el art. 13.1 C.E..", FJ 3 de la STC n. ${ }^{\circ}$ 115/1987, citada. 
der dedicar toda la atención que merecerían a algunas cuestiones colaterales, y no sólo la de cual es la legitimación que posee el Estado para denegar la entrada, la permanencia o las actividades económicas de ciudadanos extranjeros en territorio español, sino también la de los requisitos a los que dicho Estado puede condicionar legítimamente esa prohibición; y en última instancia y con carácter general, la de cuales son los objetivos constitucionalmente asignados a la "política de extranjería", aunque no cabe duda de que entre objetivos tienen un lugar preeminente las normas relativas a los derechos ${ }^{47}$.

Por la misma razón, voy a obviar incluso cuestiones mucho más concretas, como si es legítimo desde una perspectiva constitucional que esa legislación sea discriminatoria en el tratamiento de los extranjeros precisamente en perjuicio de países con los que la Constitución afirma una «particular vinculación» o la pertenencia a una "comunidad histórica». O incluso, discriminatoria respecto de los colectivos más débiles de entre los extranjeros, como sucede cuando se permite la entrada de ciudadanos procedentes de un país que acrediten recursos suficientes y se deniega esta a los ciudadanos menos pudientes de ese mismo país.

Voy a presumir, a efectos discursivos, que el Estado posee esa legitimación para establecer los requisitos de acceso y/o permanencia de extranjeros en territorio nacional y que, en cumplimiento de los objetivos constitucionalmente atribuidos a la legislación de extranjería, decide prohibir la entrada y/o permanencia de aquellos extranjeros que no cumplan los requisitos legalmente establecidos al efecto. Los extranjeros que sí los cumplan, obtendrán las correspondientes autorizaciones y sus condiciones de entrada y permanencia y sus actividades quedarán sometidas a dicha legislación.

\section{LA CONDICIÓN DE «INMIGRANTE IRREGULAR»: RESPONSABILIDAD}

Sin embargo, supongamos que existe un colectivo de extranjeros, que por diversas razones, en cuya valoración no podemos entrar, decide arriesgarse a entrar en el país o a permanecer en él sin cumplir los requisitos legales, utilizando medios que, por el momento, vamos a calificar de irregulares. Los poderes públicos tendrían en tal caso, sin duda, el derecho y no sólo el derecho, sino el deber, de cumplir y hacer cumplir la ley; y por lo tanto, la obligación de impedir, por supuesto que utilizando siempre medios legítimos y proporcionados, esa entrada;

${ }^{47}$ Y especialmente los ya mencionados artículos 14.2 de la Constitución Española y 13.2 de la Declaración Universal de los Derechos Humanos. 
y tendrían el derecho y el deber también de proceder a la repatriación de dichas personas.

Para proceder a dicha repatriación, en el caso de que se haga contra la voluntad del afectado, puede resultar necesario en algunas ocasiones restringir su libertad. En tales circunstancias, sería legítima la adopción de medidas como el confinamiento provisional de los irregulares, pero dicho confinamiento, al suponer una privación del derecho fundamental a la libertad, ha de limitarse en el tiempo al período mínimo imprescindible y ha de desarrollarse en unas condiciones acordes a la dignidad que proclama el art. 10.2 de la Constitución, sin olvidar que dicho precepto la proclama respecto de todas las personas y no sólo de los nacionales.

Desde esta perspectiva, la configuración actual de los centros de internamiento para extranjeros resulta jurídicamente inadmisible. Especialmente si se tiene en cuenta que no se trata de centros penitenciarios, aunque ni siquiera para estos serían admisibles las condiciones de hacinamiento. Pero es que además, quienes están confinados, no lo están en función de haber cometido un delito contra la legalidad vigente, sino de haber ejercido un derecho reconocido por aquella, aunque sin haber obtenido una autorización administrativa o habiendo vencido esta.

Y si la actual gestión de los centros de internamiento nacionales resulta difícilmente compatible con nuestros valores constitucionales, ¿qué se puede decir de los centros de confinamiento en países de tránsito que están impulsando las autoridades españolas y europeas en general y a los que se envía a estos ciudadanos extranjeros que no pretenden sino ejercer su derecho a migrar y que acaban viendo conculcados sus mas elementales derechos? No es en absoluto admisible la complicidad e incluso el impulso por parte de las autoridades de un Estado de derecho de este tipo de prácticas.

Pero como se ha dicho, no podemos abordar aquí en detalle todas estas cuestiones y debemos centrarnos exclusivamente en una, ya que el núcleo del problema que plantea la situación de los extranjeros irregulares se deriva no del funcionamiento de las previsiones legales de cierre de fronteras y repatriación de quienes carezcan de autorización sino precisamente de los fracasos en la implementación de dichas previsiones. Se trata concretamente de que esos poderes públicos no consiguen en algunos casos cumplir los objetivos que les han sido asignados por la legislación de extranjería y no logran repatriar a todos los extranjeros que acceden por medios irregulares. Ese colectivo de extranjeros que han accedido al territorio nacional sin la pertinente autorización o han dejado de tener la autorización que poseían en su momento, queda abocado a una situación que resulta irregular, pero no ilegal, porque en un Estado de derecho, nadie esta al margen de la ley. 
¿En quien recae la responsabilidad de su situación? Considero que la responsabilidad de esa situación irregular recae en primer lugar, en los poderes públicos, ya que, o bien han actuado negligentemente en la ejecución de las leyes o bien han legislado objetivos que no se compadecen con la realidad social sobre la que las normas deben actuar. La responsabilidad del particular, la de quien no pretende sino ejercer un derecho, aunque no haya obtenido la correspondiente autorización administrativa, o la haya perdido, es sin duda secundaria en relación a aquella.

Y considero también que no se puede entender dicha responsabilidad de la Administración decaída por la mera realización de un trámite formal, como es la entrega al extranjero de una orden de expulsión. La mera entrega de un documento de estas características no exonera a la Administración de su responsabilidad para trasladarla sobre su destinatario. Y no lo hace, por una parte, porque la realización de ese trámite formal no agota la obligación de la Administración de garantizar la efectividad material de los objetivos que le imponen las leyes. Y por otra, porque es evidente que para quien ha accedido al país prescindiendo de principio de la autorización de entrada o permanece en el habiéndola perdido, nada varía en su relación con la autoridad porque se le haga saber que debe abandonarlo.

En consecuencia, dicho trámite administrativo no altera en mi opinión la situación anterior, ya que la responsabilidad del particular y la de la Administración siguen siendo las mismas que antes de él. La del particular, porque la ignorancia de las leyes no excusa de su cumplimiento y por lo tanto, si las leyes establecen la exigencia de la preceptiva autorización, no es necesario informar personalmente a un extranjero de que no puede entrar y/o permanecer en territorio español sin permiso de las autoridades españolas. Y la de la Administración, porque conociendo que la situación irregular se deriva del incumplimiento por el particular de la obligación de obtener autorización para la estancia, resultaría negligente presumir que esta situación vaya a alterarse por la mera comunicación de que, al no poseer permiso para la estancia, deba abandonar el país. Y todo ello, aún obviando las condiciones fácticas en que se desarrolla la relación administrativa, ya que en muchos de los casos, el particular no podría volver a su país ni aunque poseyera una voluntad en tal sentido, al carecer de los medios necesarios para hacerlo.

Por si cupiera alguna duda al respecto, las propias directrices administrativas en materia de extranjería han venido a confirmar el hecho de que la orden de expulsión no traslada la responsabilidad de la Administración sobre el afectado, llegando al extremo de conferir a dicha orden incluso efectos favorables a este. Así ha sucedido en algún caso en el desarrollo de un proceso de regularización, en el que se ha atribuido a las órdenes de expulsión no ejecutadas eficacia como «do- 
cumento público fehaciente» de cara a obtener el empadronamiento por omisión, empadronamiento que constituía, a su vez, un requisito administrativo exigido a efectos de cómputo del tiempo de permanencia en el país.

En resumen, podemos concluir que el libramiento de una orden de expulsión no libera a las autoridades de su obligación de proceder a la repatriación o permitir la estancia en condiciones regulares. Y podemos concluir también que corresponde a esas mismas autoridades que no han sido eficaces impidiendo la entrada irregular la iniciativa para restablecer las grietas que han provocado en el imperio de la ley.

Es más, si la legislación de extranjería regula la prohibición de entrada y permanencia para aquellos extranjeros que no pueden acreditar medios suficientes de subsistencia, la consecuencia lógica es que reconozcamos la existencia de una presunción de carácter general, aunque de eficacia únicamente «iuris tantum", de estado de necesidad de la persona que opta por entrar en el país de forma irregular y asumiendo, en consecuencia, importantes riesgos personales y patrimoniales. Porque, como mínimo, el extranjero que entra por medios irregulares arriesga un importante patrimonio que, en muchos casos, excede la integridad del patrimonio personal e incluso familiar, llegando a niveles de enorme endeudamiento. Además, arriesga generalmente su seguridad y a veces incluso su vida, ya que utiliza cauces de entrada irregulares. También arriesga su libertad, ya que en caso de ser interceptado podrá ser privado de ella y confinado hasta su repatriación.

Por todo ello, en la entrada y permanencia irregular en España de ciudadanos extranjeros, considero que debe entenderse que existe con carácter general una presunción de inocencia, derivada del hecho de que el incumplimiento de la obligación de obtener autorización administrativa trae su causa en un estado de necesidad, porque quien se ve forzado a abandonar su país y a asumir todos esos riesgos personales, debe presumirse que actúa en tal estado. Ello no implica en absoluto el reconocimiento de que todas las entradas irregulares sean inocentes. Es evidente que no todas lo son. Incluso algunas pueden tener su origen precisamente en una intencionalidad delictiva o de eludir la acción de la justicia internacional o de un país extranjero. La presunción de inocencia no constituye, por lo tanto, una presunción «iuris et de iure», sino sólo «iuris tantum», de forma que en algún caso, se podrá probar que alguien accedió de forma irregular sin estar compelido a ello ni tener una causa legítima. En todo caso, lo que no puede admitirse con carácter general es la otra alternativa, la presunción de culpabilidad, ya que supondría considerar que una decisión que conlleva tantos riesgos como la de la emigración clandestina pueda adoptarse por capricho y por lo tanto, se hará necesario probar la culpabilidad en cada caso. 
En todo caso y al margen de la eventual carga de responsabilidad que pueda corresponder al inmigrante que accede y/o permanece en territorio español de forma irregular, parece evidente que corresponde a los poderes públicos resolver esa irregularidad y restablecer el imperio de la ley. Para ello disponen de dos medios, que pueden ser alternativos. El primero es, como se ha visto, el de la repatriación de los extranjeros en situación irregular, una repatriación que puede ser o bien pactada o bien forzosa; y el segundo, el de la regularización de estos. En todo caso, dentro del Estado de derecho no pueden existir limbos jurídicos. ¿Qué sucede entonces en el entretiempo hasta que una de estas medidas sea adoptada? ¿Qué status poseen los extranjeros que accedieron por vías irregulares a territorio español?

\section{DERECHOS DE LOS INMIGRANTES IRREGULARES}

Mientras permanecen en esa situación de interinidad, los inmigrantes irregulares no disfrutan necesariamente de todos los derechos y obligaciones que corresponden a los españoles, ni siquiera de todos los que corresponden a los extranjeros que accedieron de forma regular y disponen de permiso de residencia; y ello porque existen diversas fuentes, tanto nacionales como internacionales, de atribución de derechos y algunas de estas normas tienen en cuenta la pertenencia del individuo o las condiciones de entrada al país para realizar la atribución.

Precisamente por eso, no es fácil realizar una caracterización detallada de los derechos aplicables a cada uno de los colectivos mencionados. En todo caso y para evitar los errores que en esta materia frecuentemente se derivan de visiones parciales del ordenamiento jurídico, conviene advertir en primer lugar de que la legislación de extranjería es sólo una de estas fuentes de atribución de derechos, pero no la única, ni siquiera la principal. Y se debe advertir también de que se trata de una fuente necesariamente contingente y que lo está siendo aún más en España por diversas causas de índole socio-política. Por todo ello, resulta imprescindible no incurrir en el error de derivar los derechos de los extranjeros de la legalidad nacional de naturaleza ordinaria, en nuestro caso la Ley de extranjería y los reglamentos que la desarrollan, como desgraciadamente sucede con demasiada frecuencia. Para evitarlo, es necesario tener en cuenta que existen fuentes de atribución de derechos de rango superior y que no se debe presumir la adecuación entre estas y las de rango inferior.

La principal fuente de atribución es la propia Constitución, ya que ella proporciona los criterios generales sobre los derechos de todas las personas en 
nuestro país y por tanto, también de los extranjeros ${ }^{48}$; de forma que el núcleo básico de derechos de que disponen los extranjeros en España viene configurado en sede constitucional ${ }^{49}$, entendiendo que cuando se habla de sede constitucional nos estamos refiriendo también al conjunto de derechos atribuidos por normas jurídicas de rango internacional, pero que se integran en dicha sede a través de los artículos 10.1 y 10.2, de forma que la posesión de derechos en el ámbito nacional no puede interpretarse de forma distinta a la atribución internacional. Dicho esto, cabe advertir de entrada que la concreción de este núcleo de derechos a partir de nuestra ley fundamental, interpretada de acuerdo con la Declaración universal de derechos humanos, no resulta una tarea fácil por diversas razones.

No es tarea fácil, en primer lugar, porque la DUDH constituye una norma del rango más elevado pero, aunque ello la haga incuestionable desde criterios de validez jurídica, su virtualidad, como sucede con todas las normas, depende de la eficacia que despliegue la amenaza de uso de la fuerza que lleva implícita toda norma y hoy por hoy no cabe duda de que esa fuerza sigue básicamente en manos del Estado y sólo muy limitadamente de la comunidad internacional, de forma que el cumplimiento o la eventual conculcación de los derechos que tipifica, va a verificarse básicamente en sede nacional y a través de la justicia nacional.

En segundo lugar, dificulta la concreción del entramado de derechos de los extranjeros la falta de claridad al respecto de la Constitución de 1978, falta de claridad que se debe a su vez, en mi opinión a dos hechos. Por una parte, a las deficiencias técnicas de las que adolece la regulación de los derechos en la ley fundamental; y por otra, a la escasa atención que esta dedica a la problemática de la extranjería, lo que se justifica en el hecho de que la irrupción del fenómeno de la inmigración constituye una realidad reciente en España, de forma que el legislador constituyente no pudo prever en su momento las dimensiones que este iba a adquirir.

En tercer lugar, conviene apuntar el hecho de que dichas deficiencias podían haber sido colmadas por una jurisprudencia constitucional nítida, que hubiera concretado los perfiles admisibles para el desarrollo legislativo ordinario. Sin embargo, la jurisprudencia en la materia del alto tribunal no se ha caracterizado en estos años ni por la constancia, ni desgraciadamente en mi opinión, por el rigor garantista con el que sí ha abordado en cambio otros ámbitos relativos a los derechos fundamentales.

48 AJA, ELISEO, http://www.lafactoriaweb.com/articulos/Aja5.htm

49 Como afirma expresamente la propia Constitución, cuando dice que "Los extranjeros gozarán en España de las libertades públicas que garantiza el presente Titulo...» (art. 13.1). 
Por último, la legislación ordinaria en materia de extranjería y los correspondientes reglamentos de desarrollo tampoco han tenido una inspiración garantista, sino que ambos han ido dando constantes bandazos, con sucesivas reformas legislativas y reglamentarias de escaso calado y realizadas en función de criterios puramente oportunistas, cuando no incluso demagógicos, pero en todo caso, bastante alejados de los valores superiores que inspiran nuestro ordenamiento jurídico.

Hechas estas advertencias, voy a intentar abordar algunos de los aspectos que en mi opinión integran el régimen constitucional básico de la extranjería, argumentándolos en torno a los criterios que el Tribunal Constitucional ha venido estableciendo al respecto.

En primer lugar, considero que el tribunal, a la hora de reconocer el régimen constitucional de los extranjeros no ha partido de una visión suficientemente contextual, sino que ha pretendido deducir dicho régimen casi exclusivamente del artículo 13 de la Constitución. En mi opinión, la concreción de dicho régimen debería haberse inspirado en la integridad del entramado constitucional de derechos, interpretado a la luz de los valores superiores de nuestro ordenamiento jurídico y de la Declaración universal de los derechos humanos. El artículo 13 es sin duda, parte importante de este entramado, pero, al menos desde la mencionada perspectiva garantista, no parece lo más adecuado deducir el conjunto de derechos que corresponden a una persona a partir casi exclusivamente de este precepto y a partir además de una interpretación que no se caracteriza precisamente por su carácter expansivo.

Por otra parte, la jurisprudencia constitucional tampoco ha sido demasiado constante en materia de derechos de los extranjeros. Ha habido pronunciamientos con diferencias no sólo de matiz, sino radicalmente contradictorios entre ellos. Voy a tratar de examinar los derechos de los extranjeros en España y como han sido estos interpretados por el Tribunal Constitucional desde dos perspectivas diferentes, la de la naturaleza que poseen estos y la de su contenido, ya que la primera de ellas supone una cuestión previa que condiciona la segunda.

\subsection{Naturaleza}

La de la naturaleza de los derechos de los extranjeros en España constituye una cuestión litigiosa y que en mi opinión, no ha sido suficientemente aclarada por el Tribunal Constitucional, de cuyos posicionamientos se pueden obtener argumentos tanto a favor como en contra de su consideración como derechos constitucionalmente blindados. A favor de tal interpretación esta el hecho de que 
desde sus primeros pronunciamientos, el tribunal afirmara la naturaleza constitucional y no simplemente legal de estos derechos. Y lo hiciera en unos términos que resultan contundentes: «los derechos y libertades reconocidos a los extranjeros siguen siendo derechos constitucionales y por tanto, dotados - dentro de su específica regulación- de la protección constitucional $»^{50}$. Insiste además el alto tribunal en que las diferencias de trato del artículo 13 CE no deben interpretarse en el sentido de que «se haya querido desconstitucionalizar la posición jurídica de los extranjeros relativa a los derechos y libertades públicas" ${ }^{51}$.

En resumen, estos pronunciamientos parecen no dejar lugar a dudas respecto de la claridad con que el tribunal asume que la Constitución es la principal fuente de atribución de derechos a los extranjeros, de forma que el núcleo básico de derechos de estos viene ya prefigurado en aquella. Hecha esta primera aclaración, conviene examinar en segundo lugar la entidad que se atribuye a dicho reconocimiento constitucional. Y a ese respecto, la mencionada rotundidad parece desdibujarse, como puede constatarse en algunas consideraciones contenidas en la misma sentencia.

Así sucede cuando el mismo afirma que los derechos de los extranjeros «son todos ellos sin excepción en cuanto a su contenido derechos de configuración legal ${ }^{52}$. Si entendemos como derechos de configuración legal aquellos cuyo reconocimiento en sede constitucional no les atribuye efectos instantáneos para el particular, quedando estos diferidos al momento de la intervención del legislador ordinario, el cual, al regularlos, les atribuye unas premisas de ejercicio y un contenido concreto, resulta evidente que tal caracterización no encaja con algunos de los derechos que poseen los extranjeros en España. En efecto, respecto de algunos de estos derechos, su mero reconocimiento constitucional despliega efectos inmediatos y previos a la «interpositio legislatoris». Por ejemplo, el derecho a la vida o a la integridad física de los extranjeros. Es evidente que su reconocimiento constitucional despliega efectividad jurídica inmediata, sin necesidad de remisión a la legislación ordinaria.

Pero es que además, el tribunal se refiere a los derechos de los extranjeros como derechos de configuración legal no sólo en el sentido de no inmediatez de su reconocimiento, sino también en el de una libertad absoluta de configuración por parte del legislador ordinario, afirmando que «el disfrute de los derechos y libertades (...) reconocidos en el Título I de la Constitución se efectuará en la medida en que lo determinen los tratados internacionales y la Ley interna españo-

${ }^{50}$ STC n. $^{\circ}$ 107/1984, de 23 de noviembre, B.O.E. n. ${ }^{\circ}$ 305/1984, de 21 de diciembre ; FJ 3.

51 Idem.

${ }^{52}$ FJ 3. de la STC n. ${ }^{\circ}$ 107/1984, cit. 
la, y de conformidad con las condiciones y el contenido previsto en tales normas $»^{53}$, argumento que confirma en sentencia posterior en la que afirma que «el ejercicio por los extranjeros de derechos y libertades públicas puede sufrir limitaciones, siendo el límite que se impone al legislador el reconocimiento del estándar mínimo que prescriben los Tratados internacionales» ${ }^{54}$.

¿Significa todo esto que el reconocimiento constitucional de un derecho puede entenderse en algún caso sin atribución de un núcleo esencial o contenido mínimo indisponible por parte del legislador ordinario? En tal caso, si el legislador careciera de condicionante alguno, el reconocimiento constitucional equivaldría al no reconocimiento o lo que es lo mismo, se estaría admitiendo implícitamente que existen preceptos constitucionales no vinculantes jurídicamente, lo cual constituye, sin duda, una incongruencia dogmática ${ }^{55}$.

De tales pronunciamientos se podrían haber derivado consecuencias peligrosísimas, ya que planteaban prácticamente un cheque en blanco para el legislador ordinario en la regulación de los derechos de los extranjeros. Para conjurar este riesgo, hay que tener en cuenta otras afirmaciones del propio Tribunal que resultan incompatibles con esa idea de discrecionalidad, como cuando refiriéndose a algunos de estos derechos, concretamente a «los que pertenecen a la persona en cuanto tal... por ser imprescindibles para la garantía de la dignidad humana" ${ }^{56}$, afirma que "corresponden a los extranjeros por propio mandato constitucional, y no resulta posible un tratamiento desigual respecto a ellos en relación a los españoles» ${ }^{57}$. En consecuencia, los derechos humanos más básicos, los implícitos en el artículo 10.1, entre los cuales se encuentran «el derecho a la vida, a la integridad física y moral, a la intimidad, la libertad ideológica, etc.» quedan atribuidos a los extranjeros «ex constitutionem» y quedan además atribuidos en igualdad absoluta de condiciones respecto de los españoles.

En sentencias posteriores, el tribunal siguió perfilando sus primeros pronunciamientos, diciendo que el art. 13.1 «no significa que los extranjeros gozarán sólo de aquellos derechos y libertades que establezcan los tratados y las leyes ${ }^{58}$, sino que "el disfrute por los extranjeros de los derechos y libertades reconocidos en el Título I de la Constitución... podrá atemperarse en cuanto a

53 Idem.

${ }^{54}$ STC n. ${ }^{\circ} 115 / 1987$, de 7 de julio, B.O.E. n. ${ }^{\circ} 180 / 1987$, de 29 de julio.

55 Sobre el valor normativo de la Constitución, véase por todos, García de Enterría: «La Constitución como norma y el Tribunal Constitucional», Madrid, 2006.

56 FJ 3 de la citada sentencia 107/1984.

57 Idem

58 STC n. ${ }^{\circ}$ 99/1985, de 30 de septiembre, B.O.E. n. ${ }^{\circ}$ 265/1985, de 5 de noviembre. FJ 2. 
su contenido a lo que determinen los tratados internacionales y la Ley interna española" "; ; aunque resulta evidente que en este caso el uso del término "atemperar» no es muy afortunado, ya que las normas ordinarias no pueden propiamente atemperar las previsiones constitucionales, por lo que habría que interpretarlo en el sentido de desarrollarlas o concretarlas. Por otra parte, el alto tribunal también ha declarado inconstitucionales artículos de normas ordinarias ${ }^{60}$ por desconocer el "contenido preceptivo e imperativo" de los derechos reconocidos a los extranjeros en el Título I de la Constitución ${ }^{61}$.

En resumen y a pesar de los equívocos iniciales en los pronunciamientos del Tribunal Constitucional, que posteriormente se han ido matizando y a pesar incluso de las discrepancias dentro de este formuladas en votos particulares contrarios a la doctrina mayoritaria ${ }^{62}$, resulta evidente que los extranjeros disponen en España de un núcleo básico de derechos constitucionales, conformado, por una parte, por los derechos inherentes a la dignidad humana del artículo $10 \mathrm{y}$ por otra, por el resto de previsiones constitucionales que les atribuyen derechos ${ }^{63}$ y que dicho núcleo crea un ámbito de indisponibilidad para el legislador ordinario, incluso sin necesidad de recurrir al condicionante de los tratados internacionales en la materia.

Este núcleo básico de derechos conforma lo que podemos denominar como el estatuto constitucional de la extranjería, un estatuto que puede y debe ser desarrollado por la legislación ordinaria, atendiendo a los objetivos constitucionalmente atribuidos a los poderes públicos dentro del Estado social y democrá-

59 Idem.

${ }^{60}$ Concretamente, la Ley Orgánica 7/1985, de 7 de julio, de extranjería.

${ }^{61}$ STC n. ${ }^{\circ} 115 / 1987$, cit. FJ 2.

${ }^{6}$ Estas discrepancias se han manifestado nítidamente en la sentencia recientemente recaída en el recurso del Parlamento de Navarra contra la Ley de extranjería (Ley orgánica 8/2000, de 22 de diciembre), en el que varios magistrados secundan un voto particular oponiéndose frontalmente a la jurisprudencia del tribunal en materia de derechos constitucionales de los extranjeros y afirmando que el estatuto de los extranjeros que establece el art. $13 \mathrm{CE}$, «remite en primer lugar a los Tratados, y en segundo lugar a la Ley», de lo que deducen que los tratados constituyen «el único límite discernible que la Constitución fija al legislador». En consecuencia, los discrepantes consideran que no cabe controlar la legitimidad constitucional de las limitaciones de los derechos de los extranjeros en los casos en que dichas limitaciones estén autorizadas por los propios tratados que reconocen los derechos correspondientes — voto particular que formula el magistrado Conde Martín de Hijas a la STC 236/2007, de 7 de noviembre, BOE n. ${ }^{\circ}$ 295/2007, de 10 de diciembre-.

${ }^{63}$ Que no son sólo aquellas que explícitamente mencionan a los extranjeros, sino las que no hacen mención explícita de los españoles como destinatarios, utilizando términos como «todos», «todas las personas» u otros análogos. 
tico de derecho. $Y$ en el cumplimiento de dichos objetivos, se deberá ir ampliando ese núcleo de derechos, en función de la propia capacidad del Estado de ofrecer cobertura a nuevas necesidades humanas y en función también de las prioridades que establezcan las mayorías parlamentarias en cada momento, ya que el propio carácter abierto de la Constitución permite "políticas de extranjería» diferentes, dentro del respeto al marco constitucional, un marco constitucional que, en todo caso, blinda ese núcleo mínimo de derechos.

Y ello porque dicho estatuto constitucional, tal como establece expresamente el mandato del art. 53.164, vincula a todos los poderes públicos y determina además una reserva de ley en dicho ámbito, con la consecuencia de que el legislador ordinario no actúa con discrecionalidad al concretar aquellos derechos, sino que debe legislar atendiendo, con carácter general, los valores superiores de nuestro ordenamiento jurídico y los objetivos constitucionalmente atribuidos a la acción de los poderes públicos; y en particular, debe respetar escrupulosamente el núcleo esencial de aquellos derechos asignados «ex constitutionem» a los extranjeros.

\subsection{Contenido}

$\mathrm{Al}$ igual que con la jurisprudencia relativa a la naturaleza de los derechos de los extranjeros, algo parecido sucede con su contenido. Los pronunciamientos del Tribunal no siempre son nítidos al respecto. Además, cuando lo han sido, ha habido votos particulares discrepantes, que no han hecho sino evidenciar las divergencias doctrinales al respecto. Y por último, ha habido una importante evolución desde los primeros pronunciamientos hasta la actualidad, una evolución que podemos calificar como de corte garantista, ya que ha supuesto, por una parte, el reconocimiento progresivo de un número de derechos cada vez mayor y por otra, el reconocimiento de mayores contenidos a estos derechos y en general al principio de igualdad de trato en relación al disfrute de los derechos. Esta evolución ha llegado a su máxima expresión cuando el TC ha afirmado que "con la mejor doctrina habría que presumir, en principio, la equiparación del ejercicio de los derechos de los nacionales y de los extranjeros, y que las posibles limitaciones habrían de tener carácter excepcional, e interpretarse restrictiva-

64 «Los derechos y libertades reconocidos en el Capítulo II del presente Título vinculan a todos los poderes públicos. Sólo por Ley, que en todo caso deberá respetar su contenido esencial, podrá regularse el ejercicio de tales derechos y libertades que se tutelarán de acuerdo con lo previsto en el artículo 161,1 a)». 
mente» ${ }^{65}$. Se trata, sin duda, de una presunción «iuris tantum», ya que es evidente que en nuestro sistema constitucional no existe una equiparación total de derechos entre los españoles y los extranjeros ${ }^{66}$. Al respecto, se ha consolidado tanto en la jurisprudencia como en la doctrina, la clasificación tripartita contenida en la sentencia 107/1984 del TC: existen derechos que corresponden por igual a españoles y extranjeros y cuya regulación ha de ser igual para ambos; existen derechos que no pertenecen en modo alguno a los extranjeros (los reconocidos en el art. 23 de la Constitución, según dispone el art. 13.2 y con la salvedad que contiene); y existen otros que pertenecerán o no a los extranjeros según lo dispongan los tratados y las leyes, siendo entonces admisible la diferencia de trato con los españoles en cuanto a su ejercicio.

En resumen, los derechos constitucionales de los extranjeros se dividirían en dos tipos: aquellos de los que gozan necesariamente en condiciones de igualdad con los nacionales y aquellos otros de los que no. Al afirmar la existencia de un grupo de derechos de contenido indiferenciado para ambos colectivos, el tribunal ha realizado una interpretación amplia del estatuto constitucional de los extranjeros; una interpretación según la cual, en relación a algunos de estos derechos, el legislador ordinario no sólo viene constreñido por el necesario respeto del núcleo esencial del derecho y de los tratados internacionales, sino que además debe legislar en condiciones de igualdad absoluta para unos y otros. De forma que la igualdad no se afirma sólo respecto del núcleo esencial del derecho o respecto de su estatuto internacional mínimo, cuestión sobre la que no cabe duda alguna, sino también respecto de cualquier desarrollo adicional que el legislador quiera incorporar a aquel, aspecto sobre el cual el Tribunal no ha sido unánime ${ }^{67}$.

En segundo lugar estarían aquellos derechos respecto a los cuales puedan establecerse limitaciones a su ejercicio por los extranjeros. Pero ni siquiera respecto de estos el legislador es enteramente libre al establecer estas limitaciones, ya que tales derechos siguen siendo constitucionales; y se ha de respetar el conte-

${ }^{65}$ STC n. ${ }^{\circ} 115 / 1987$, cit. FJ 2.

${ }^{66}$ "Cuando el art. 14 de la Constitución proclama el principio de igualdad, lo hace refiriéndose con exclusividad a «los españoles». Son éstos quienes, de conformidad con el texto constitucional, «son iguales ante la Ley», y no existe prescripción ninguna que extienda tal igualdad a los extranjeros». FJ 3 de la STC n. ${ }^{\circ}$ 107/1984, cit.

${ }^{67}$ Así, por ejemplo, los magistrados Rubio Llorente, Tomás y Valiente y García Mon, consideraban en el voto particular a la ya citada STC 115/1987 que, incluso respecto de los derechos vinculados a la dignidad, el legislador no está obligado a un tratamiento igual para los extranjeros, sino sólo al respeto del contenido mínimo del derecho tal y como lo garantizan los tratados internacionales, pudiendo introducir restricciones al ejercicio de estos derechos por parte de los extranjeros, siempre y cuando se trate de restricciones legítimas. 
nido esencial del derecho de que se trate. Y conviene recordar aquí lo afirmado por el TC con carácter general en relación a las restricciones de derechos: que la restricción legal deja de estar amparada constitucionalmente si convierte al derecho proclamado en una pura apariencia de lo que es en realidad, si lo desvirtúa de forma que lo hace inaprehensible, si lo desnaturaliza y borra los perfiles con que está caracterizado $(115 / 87,2)$.

Como consecuencia de lo anterior, se puede afirmar que la completa igualdad de derechos entre españoles y extranjeros en lo relativo a derechos y libertades públicas se produce en aquellos que pertenezcan a la persona humana en cuanto tal. Pero los límites y garantías que la Constitución impone al legislador en la regulación de las restantes libertades públicas que se reconocen al extranjero no son los mismos, al quedar excluida la aplicación de la igualdad formal como parámetro al que han de ajustarse en todo caso las consecuencias y ser admisible la diferencia de trato con los españoles en cuanto a su ejercicio. En todo caso, ya se ha mencionado anteriormente que dicha desigualdad formal debe ser ponderada con el mandato de igualdad material del art. 9.2.

En resumen, los extranjeros irregulares disponen en España de los derechos constitucionales vinculados a la dignidad — con un estándar igual al de los españoles - y de cualquier otro que les confiera el legislador — con las restricciones que considere oportunas, siempre que se trate de restricciones legítimas-. Concretando un poco, más, ¿qué derechos podemos incluir en el primer grupo? Pues la respuesta no es sencilla, ya que la jurisprudencia del alto tribunal menciona algunos de ellos, pero sin llegar a enumerarlos con pretensiones de exhaustividad. Menciona en concreto el derecho a la vida, a la integridad física y moral, a la intimidad y la libertad ideológica ${ }^{68}$. Pero no se trata, por supuesto, de una lista cerrada, ya que es evidente que también los derechos al honor, a la intimidad y a la propia imagen están necesariamente vinculados a la dignidad. Entonces, ¿qué derechos puede considerarse que "pertenecen a la persona como tal y no como ciudadano» por ser «imprescindibles para la garantía de la dignidad humana»? No se me ocurre otra interpretación que aquella a la que remite expresamente la Constitución en su artículo 10.2, de forma que habría que considerar como derechos de la persona todos los derechos que considera como tales la Declaración universal de derechos humanos. De forma que, siguiendo la lógica del Tribunal Constitucional, se debería haber llegado a la conclusión de que todos los derechos reconocidos en dicha declaración son de aplicación en España para los extranjeros irregulares y lo son además con un estándar equivalente al que el ordenamiento español otorga a los nacionales. En consecuencia, si

${ }^{68}$ FJ 3 de la STC 107/1984, citada. 
nos atenemos a los criterios que el Tribunal ha establecido, deberíamos concluir que los extranjeros, mientras permanezcan en territorio español y al margen de las autorizaciones administrativas de que dispongan, poseen todos los derechos de la personalidad — no los de ciudadanía - en igualdad de condiciones. Y entre estos derechos estaría incluso el derecho que es la principal aspiración en general de los inmigrantes irregulares, el derecho al trabajo, reconocido en artículo 23 de la declaración universal.

Aunque la anterior conclusión parezca lógica desde la propia línea argumentativa del alto tribunal, no van en esa dirección ni los posicionamientos concretos de este, ni la legislación orgánica de desarrollo de los derechos de los extranjeros. Incluso la última ley de extranjería, a pesar de ser menos dura que la anterior, realiza una regulación absolutamente restrictiva de los derechos de los extranjeros, haciendo además una distinción en algunos de estos derechos entre la titularidad y el ejercicio, de forma que aunque reconoce el derecho a los extranjeros, sustrae su exigibilidad a quienes carecen de autorización de residencia; aunque respecto de otros derechos, realiza una equiparación entre sus titulares, obviando la mencionada circunstancia.

Tanto la regulación restrictiva que realiza la ley, como la exclusión de los irregulares del disfrute de la mayoría de los derechos proclamados, no parecen casar en absoluto con la filosofía garantista propia del Estado social que subyace la regulación constitucional de los derechos, ni con los propios criterios establecidos por el Tribunal Constitucional $-\mathrm{O}$ al menos con las derivaciones lógicas de estos-; ni siquiera lo hacen con los objetivos atribuidos a la ley en su exposición de motivos o con el propio texto del artículo 1 de la ley, que afirma que «como criterio interpretativo general, se entenderá que los extranjeros ejercitan los derechos que les reconoce esta ley en condiciones de igualdad con los españoles». El legislador insta a interpretar con criterios de igualdad una legislación que regula los derechos con criterios no de relativa sino de absoluta desigualdad, tanto entre españoles y extranjeros como incluso entre las diversas categorías de extranjeros.

En todo caso, la ley reconoce, aunque con carácter limitadísimo, algunos derechos para los extranjeros irregulares, como el derecho y el deber a la educación obligatoria; el derecho a la asistencia sanitaria básica - y en igualdad con los españoles en el caso de menores de edad- y a los servicios y prestaciones sociales básicas; el derecho a la tutela judicial efectiva con asistencia jurídica gratuita y la posibilidad de recurrir las decisiones administrativas que les afectan. En resumen, en lugar de un auténtico régimen de derechos, únicamente unas garantías procesales y una mínima cobertura asistencial. Y el resto de los derechos de los extranjeros se condiciona al otorgamiento de un permiso de residencia y/o traba- 
jo, que no es sino una autorización administrativa cuasidiscrecional, sometida por la propia ley a criterios de oportunidad, como las necesidades del mercado de trabajo.

De todo lo cual se deduce que el actual régimen legal de la extranjería no es acorde con las exigencias constitucionales en la materia y mucho menos si se acepta la interpretación del Tribunal Constitucional de que los derechos vinculados a la dignidad humana deben poseer un régimen igual para nacionales y extranjeros.

Sin embargo, el reciente pronunciamiento del Tribunal Constitucional en el recurso planteado por el Parlamento de Navarra contra diversos preceptos de la última Ley de extranjería ${ }^{69}$, aunque confirma el progreso en sentido garantista de la reciente jurisprudencia constitucional en materia de extranjería y declara inconstitucionales algunos de los preceptos de dicha ley que excluyen a los inmigrantes irregulares del ejercicio de determinados reconocidos a los extranjeros, no es en mi opinión suficientemente nítida al extraer las consecuencias que se derivan de los presupuestos del propio tribunal.

Por su propia trascendencia, el último pronunciamiento en la materia del alto tribunal ${ }^{70}$ requiere un análisis más en profundidad de cada uno de los aspectos mencionados. El primero de ellos es que la sentencia confirma la doctrina jurisprudencial de corte garantista establecida a partir de la sentencia 107/1984, antes mencionada. Y establece en consecuencia que la libertad de que dispone el legislador para regular los derechos de los extranjeros posee varias limitaciones: por una parte, debe respetar unos contenidos mínimos y por otra, las restricciones deben ser justificadas y deben serlo no genéricamente, sino en cada caso.

En cuanto al contenido indisponible, el tribunal afirma que la regulación de los derechos de los extranjeros deberá tener en cuenta «en primer lugar, el grado de conexión de los concretos derechos con la garantía de la dignidad humana...; en segundo lugar, el contenido preceptivo del derecho, cuando este venga reconocido a los extranjeros directamente por la Constitución; en tercer lugar y en todo caso, el contenido delimitado para el derecho por la Constitución y por los tratados internacionales» ${ }^{71}$.

En cuanto a las restricciones admisibles de los derechos de los extranjeros, se establecen dos condiciones: en primer lugar, «las condiciones de ejercicio esta-

69 Ley Orgánica 8/2000, de 22 de diciembre, de reforma de la Ley Orgánica 4/2000, de 11 de enero, sobre derechos y libertades de los extranjeros en España y su integración social.

70 STC 236/2007, de 7 de noviembre, cit.

71 FJ 4 de la STC 236/2007, cit. 
blecidas por la Ley deberán dirigirse a preservar otros derechos, bienes o intereses constitucionalmente protegidos y guardar adecuada proporcionalidad con la finalidad perseguida ${ }^{72}$. Pero además, no basta con alegar una finalidad legítima, como es la garantía del orden público, para restringir un derecho con carácter general a los extranjeros, «ya que no cabe una interpretación extensiva de dicho límite ${ }^{73}$, sino que debe justificarse la limitación en cada caso concreto.

Pues bien, en consecuencia con los anteriores postulados, la corte declara la inconstitucionalidad de diversos preceptos de la mencionada ley de extranjería; en concreto, los artículos 7.1 (derecho de reunión), 8 (derecho de asociación), 11.1 (derecho a sindicarse libremente), 9.3 (derecho a la educación) y 22.2 (derecho a la asistencia jurídica gratuita). Todos estos preceptos, a pesar de su estructura diferente, obedecen a un mismo esquema: contienen por una parte, el reconocimiento a los extranjeros de la titularidad de un derecho y por otra, la exclusión de aquellos que carecen de autorización de residencia del ejercicio de los derechos que les son reconocidos.

La tipificación de esos derechos en la Ley de extranjería es considerada inconstitucional en base a razones que podemos agrupar en tres fundamentales: en primer lugar, la atribución constitucional de dichos derechos se opera mediante la formulación genérica de «todos tienen derecho» $\mathrm{o}$ "se reconoce», es decir, sin excluir expresamente del derecho a los no nacionales y aunque la fórmula bajo la cual se hace el reconocimiento no es siempre determinante ${ }^{74}$, sí resulta al menos orientadora, e interpretada de acuerdo con la remisión a la legalidad internacional que opera el art. 10.2, resulta evidente que no hay razón alguna para considerar que «los textos internacionales excluyan a los extranjeros ilegales de todos los derechos que los Estados se comprometen a garantizar ${ }^{75}$, sino al revés, ya que sus enunciados reconocen los derechos objeto de análisis bajo fórmulas como "toda persona», "toda persona bajo la jurisdicción de un Estado», "los individuos que se encuentren en su territorio y estén sujetos a su jurisdicción»o incluso enunciados como «a nadie se le podrá negar».

En segundo lugar, el tribunal nos remite a la vinculación de cada uno de estos derechos con la dignidad humana, ya que la libertad de configuración de que dispone el legislador es limitada en relación a los derechos «imprescindibles

72 Loc. Cit.

73 FJ 6 de la STC 236/2007, cit.

${ }^{74} \mathrm{El}$ propio tribunal ha relativizado en ocasiones la dicción literal de los artículos que reconocen derechos, como por ejemplo, en la STC 94/1993, de 22 de marzo, BOE 100/1993, de 27 de abril.

75 FJ 6 de la STC 236/2007, cit. 
para la garantía de la dignidad humana ${ }^{76}$, aunque la corte no es unánime en la interpretación de este criterio ${ }^{77}$. Y el tribunal, al analizar el contenido de los derechos de reunión, asociación y tutela judicial considera que poseen un grado de conexión esencial con la dignidad. En el caso del derecho a la educación, considera además que la instrucción básica no agota el contenido esencial del derecho, que debe ser considerado en el sentido de que a nadie se le puede prohibir el acceso a la educación en su integridad ${ }^{78}$. En cuanto al derecho a la libre sindicación, no se afirma expresamente su vinculación a la dignidad, pero se hace extensivo a los extranjeros irregulares el reconocimiento que ya venía haciendo el tribunal de la titularidad del derecho a todos los trabajadores «en su caracterización material y no jurídico-formal» ${ }^{79}$, de forma que habría que presumirlo como derecho conexo a la dignidad del trabajador.

En tercer lugar, el tribunal considera que entre las «condiciones de ejercicio» de los derechos que el legislador puede establecer y que deben ser constitucionalmente legítimas y además proporcionadas, sí se encuentra la garantía del orden público o seguridad ciudadana; pero afirma también que no cabe realizar «una interpretación extensiva de dicho límite, incluyendo en el mismo la regularidad de los extranjeros en España», sino que, en el caso de limitaciones al principio de libertad, debe resultar en cada caso «indubitablemente probado que se ha traspasado efectivamente el ámbito de libertad constitucionalmente fijado» ${ }^{80}$. En resumen, la seguridad ciudadana condiciona el ejercicio de los derechos por parte de los extranjeros, pero la apelación abstracta a ella no es suficiente para legitimar la privación a los irregulares del ejercicio de sus derechos.

En resumen, podemos afirmar que tanto este pronunciamiento del Tribunal Constitucional como otros anteriores han venido a corregir algunos de los ex-

76 Loc. Cit., FJ 3.

77 El voto particular que formula el magistrado Conde Martín de Hijas entiende que la dignidad no puede ser un canon autónomo, sino que debe colegirse con el resto de los criterios del art. 10, es decir, los derechos inviolables, el libre desarrollo de la personalidad y el respeto a la ley y a los derechos de los demás. El autor considera que la condición de estancia legal en España «no es sino expresión inmediata del respeto a la ley», respeto incompatible según él "con una situación generalizada y masiva de incumplimiento». El argumento resulta realmente peligroso, ya que vincula el ejercicio de los derechos al cumplimiento de las leyes, además de presumir la falta de respeto por las leyes de todos los que carecen de una autorización administrativa en regla.

78 «...el contenido constitucionalmente garantizado de ese derecho, en su dimensión prestacional, no se limita a la enseñanza básica, sino que se extiende también a los niveles superiores, aunque en ellos no se imponga constitucionalmente la obligatoriedad y la gratuidad» - FJ 8 de la sentencia citada.

79 Loc. Cit., FJ 9.

${ }^{80}$ Loc. Cit, FJ 6. 
cesos de una legislación muy restrictiva en materia de derechos de los extranjeros irregulares, una legislación que no esta en mi opinión a la altura ni de las exigencias del derecho internacional de la extranjería, ni de nuestro sistema constitucional de derechos.

\title{
RESUMEN
}

El trabajo pretende analizar la situación legal en España de los inmigrantes irregulares, a partir de la jurisprudencia constitucional. El análisis se realiza básicamente desde una perspectiva constitucional, aunque se analizan también las principales normas internacionales y españolas en materia de extranjería.

El estudio comienza insertando la problemática de los inmigrantes irregulares en el marco del Estado social. Además, trata de establecer los perfiles concretos del derecho a emigrar en el derecho internacional $\mathrm{y}$ en el derecho interno. Y por último, intenta concretar los derechos que poseen los inmigrantes que permanecen en España sin autorización de residencia.

\section{TITLE}

IRREGULAR INMIGRANTS AND THEIR CONSTITUTIONAL RIGHTS

\begin{abstract}
The work tries to analyze the legal situation in Spain of the irregular immigrants starting from the constitutional jurisprudence. The analysis is realized basically from a constitutional perspective, though there are analyzed also the principal international and Spanish norms for the inmigrants.

The study starts by inserting the problematics of the irregular immigrants in the frame of the social State. In addition, it tries to establish the concrete profiles of the right to emigrate in the international law and in the internal law. And finally, it tries to make concrete the rights that there possess the immigrants who remain in Spain without authorization of residence.
\end{abstract}

\section{SUMMARY}

1. THE SOCIAL STATE BEFORE THE PHENOMENON OF THE IRREGULAR IMMIGRATION. 2. THE MIGRATION FREEDOM LIKE HUMAN RIGHT AND AS CONSTITUTIONAL RIGHT. 3. RIGHT TO EMIGRATE, RIGHT TO IMMIGRATE 
AND NATIONAL SOVEREIGNTY. 4. ACCEPTABLE RESTRICTIONS TO THE RIGHT TO IMMIGRATE. 5. «IRREGULAR» IMMIGRANT'S CONDITION: RESPONSIBILITY. 6. THE IRREGULAR IMMIGRANTS'RIGHTS. 6.1. Nature. 6.2. Content. 